Research Article

\title{
Post-mortem 7.0-Tesla Magnetic Resonance Imaging of the Hippocampus in Amyotrophic Lateral Sclerosis
}

Jacques De Reuck*, Florent Auger, Nicolas Durieux, Claude-Alain Maurage, Vincent Deramecourt, Charlotte Cordonnier, Florence Pasquier, Didier Leys, Regis Bordet

Unitè 1171 "Degenerative and vascular cognitive disorders", Université de Lille 2, Lille, France; EMails: dereuck.j@gmail.com; florent.auger@univ-lille2.fr; nicolas.durieux@univ-lille2.fr; ClaudeAlain.MAURAGE@CHRU-LILLE.FR; vderamecourt@aol.com; Charlotte.CORDONNIER@CHRULILLE.FR; Florence.PASQUIER@CHRU-LILLE.FR; Didier.LEYS@CHRU-LILLE.FR; Regis.BORDET@CHRULILLE.FR

* Correspondence: Jacques De Reuck; E-Mail: dereuck.j@gmail.com

Academic Editor: Douglas G. Walker

Special Issue: $\underline{\text { Research on Neurodegenerative Diseases }}$

OBM Geriatrics

2020, volume 4, issue 4

doi:10.21926/obm.geriatr.2004143
Received: October 12, 2020

Accepted: December 03, 2020

Published: December 17, 2020

\begin{abstract}
Amyotrophic lateral sclerosis (ALS) is reported to be probably linked to frontotemporal lobar degeneration (FTLD). Since FTLD is characterized by severe frontotemporal degeneration along with hippocampal atrophy $(\mathrm{HA})$, the present study used post-mortem 7.0-tesla magnetic resonance imaging to investigate whether a certain degree of HA occurs in the ALS brains as well. The examined post-mortem brain samples comprised 9 from the ALS cases and 17 from the age-matched controls. The hippocampus samples were examined on the most representative coronal section using $\mathrm{T} 2$ and $\mathrm{T} 2 * \mathrm{MRI}$ sequences, and the average degree of HA was determined for both groups. The occurrence of hippocampal micro-infarcts (HMIs) and hippocampal micro-bleeds (HMBs), as well as the frequency of cortical micro-infarcts (CoMls) and cortical micro-bleeds (CoMBs) in the neocortex, were compared between the groups. Considerable HA was observed in the ALS group compared to the control group. The incidence of HMIs and HMBs was low and comparable in the ALS and control groups.
\end{abstract}

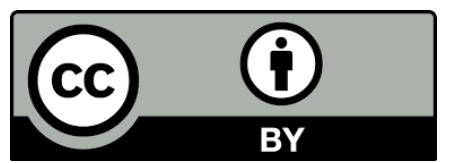

C 2020 by the author. This is an open access article distributed under the conditions of the Creative Commons by Attribution License, which permits unrestricted use, distribution, and reproduction in any medium or format, provided the original work is correctly cited. 
Moreover, the frequency of CoMls and CoMBs in the neocortex was relatively comparable in the two groups. This post-mortem observation of $\mathrm{HA}$ is an additional argument in favor of the link between ALS and FTLD. Furthermore, both ALS and FTLD share a low vascular risk profile.

\section{Keywords}

Post-mortem magnetic resonance imaging; amyotrophic lateral sclerosis; hippocampal atrophy; cortical micro-infarcts; cortical micro-bleeds

\section{Introduction}

Amyotrophic lateral sclerosis (ALS) is a neurodegenerative disease that affects motor neurons and other neuronal cells, leading to severe disability and eventually death due to ventilatory failure. ALS has a prevalence of 5 in 100,000 individuals, with an incidence of 1.7 per 100,000 individuals, reflecting a short average survival [1]. ALS is reported to be closely linked to frontotemporal lobe degeneration (FTLD) [2]. FTLD is associated with ALS in $5 \%$ to $10 \%$ cases [3, 4]. Both FTLD and ALS share an increased accumulation of iron in the deep brain structures, although to a lesser degree in ALS [5].

The in vivo evaluation of the human hippocampal volume and shape using magnetic resonance imaging (MRI) has become important in the field of neuroimaging research [6].

No significant hippocampal atrophy $(\mathrm{HA})$ is observed during normal aging. In FTLD, severe HA is observed [7]. In ALS patients, moderate HA is a frequent observation, along with intermittent cognitive dysfunction but without dementia [8, 9].

The present study used post-mortem 7.0-tesla MRI to evaluate the degree of HA and the incidence of hippocampal micro-infarcts (HMIs) and hippocampal micro-bleeds (HMBs) occurring in the ALS patients compared to the normal age-matched controls. In addition, the incidence of cortical micro-infarcts (CoMIs) and cortical micro-bleeds (CoMBs) in the hemispheric neocortex was compared between the two groups.

\section{Materials and Methods}

The post-mortem examination involved the brain samples from 9 ALS patients and 17 agematched controls, all without a history of any neurological disease. Informed consent was obtained either from the patients or their nearest family members for allowing an autopsy for diagnostic and scientific purposes. The brain tissue samples were acquired from the Lille Neuro-Bank of the Lille University, which is part of the "Centres des Resources Biologiques" and also acts as an institutional review board.

The neuropathological examination was conducted according to a standard procedure [9]. A whole coronal section of a cerebral hemisphere at the level of the mamillary body was used to determine the number of CoMls and CoMBs.

Using MRI, the degree of HA was determined according to the 4-grade classification of Scheltens for Alzheimer's disease $[10,11]$. In addition, the incidence of HMIs and HMBs was determined as described previously for the cortical hemispheric CoMls and CoMBs [12]. 
A 7.0-tesla MRI Bruker BioSpin SA with an issuer-receiver cylinder coil having a 72-mm inner diameter (Ettlingen, Germany) was used according to the method described in previous work [13]. The brain sections, previously cleaned using formalin, were placed in a plastic box filled with saltfree water, the size of which did not allow significant movements of the tissue sample. Prior to brain sampling, three to six coronal sections of a cerebral hemisphere were submitted to SPIN ECHO T2 and T2* MRI sequences, and the hippocampus was evaluated on the most representative section.

Unvaried comparisons of the unpaired groups were performed using Fisher's exact test for the categorical data. The non-parametric Mann-Whitney $U$ test was used to compare the continuous variables. The significance level, two-tailed, was set at $\leq 0.01$ for significant and $\leq 0.001$ for highly significant. The values $<0.05$ and greater than $>0.01$ were considered marginally significant.

\section{Results}

The age and gender distributions were relatively the same in the ALS patients and the controls [66 years in both groups], with an incidence of $50 \%$ males in the ALS group and $70 \%$ in the control group.

The post-mortem examination revealed that cerebral amyloid angiopathy, lobar hematomas, and lacunar infarcts were absent in both the groups. Only a small territorial cortical cerebellar infarct was observed in one brain sample in the control group. The incidence of CoMls and CoMBs was low and similar in the ALS and control groups (Table 1).

Table 1 Comparison of the demographics and the associated post-mortem neuropathology (standard deviation) between the patients with amyotrophic lateral sclerosis (ALS) and the normal controls.

\begin{tabular}{lll}
\hline Items & ALS & Control \\
\hline Number of brains & 9 & 17 \\
Age (years) & $66(3.7)$ & $66(7.9)$ \\
Male gender & $50 \%$ & $70 \%$ \\
Cerebral amyloid angiopathy & $0 \%$ & $0 \%$ \\
Lobar Hematoma & $0 \%$ & $0 \%$ \\
Territorial Infarct & $0 \%$ & $0 \%$ \\
Lacunar Infarct & $0 \%$ & $0 \%$ \\
Cortical micro-infarct & $0.3(0.5)$ & $0.2(0.5)$ \\
Cortical micro-bleed & $0.4(0.5)$ & $0.1(0.3)$ \\
\hline
\end{tabular}

The MRI revealed significantly higher severity of HA in the ALS brains compared to the control brains $(p<0.01)$, with an incidence of $1.3(0.9)$ in the former and $0.3(0.4)$ in the latter. No differences in the rates of HMIs and HMBs were observed between the two groups. In addition, a comparison of CoMls and CoMBs in the neocortex of the cerebral hemisphere presented no statistical differences (Table 2). 
Table 2 Comparison of the degree of hippocampal lesions (standard deviation) between the patients with amyotrophic lateral sclerosis (ALS) and the normal controls, along with the incidence of small cerebrovascular lesions in the hemispheric neocortex in magnetic resonance imaging.

\begin{tabular}{llll}
\hline Items & ALS & Control & P. value \\
\hline Hippocampal atrophy & $1.3(0.9)^{*}$ & $0.3(0.4)$ & $<0.01$ \\
Hippocampal micro-infarcts & $0.3(0.5)$ & $0.2(0.5)$ & N.S. \\
Hippocampal micro-bleeds & $0.1(0.3)$ & $0.1(0.3)$ & N.S. \\
Neocortical micro-infarcts & $0.1(0.3)$ & $0.1(0.3)$ & N.S. \\
Neocortical micro-bleeds & $0.6(0.8)$ & $0.4(0.7)$ & N.S. \\
\hline
\end{tabular}
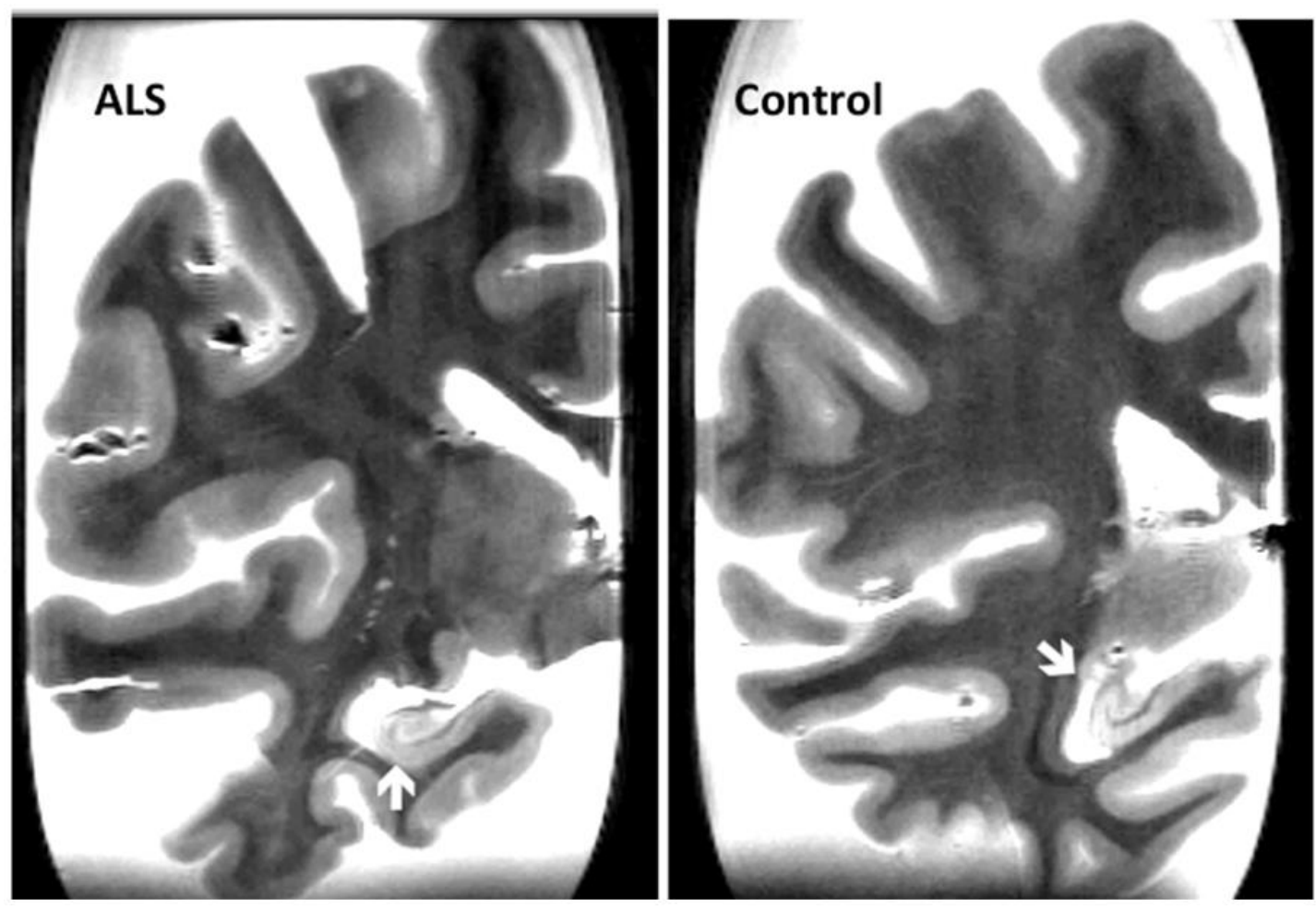

Figure 1 Comparison of a post-mortem T2 sequence magnetic resonance image of the coronal sections of a cerebral hemisphere between a brain sample with amyotrophic lateral sclerosis and a normal control one. The white arrows represent the differences in the size of the temporal horn and the hippocampus, with greater atrophy in the former.

\section{Discussion}

The post-mortem MRI results of the present study confirm the occurrence of HA in ALS patients. Previous in-vivo studies have mostly reported the occurrence of HA in ALS patients at a late stage of the disease, mainly in association with memory disturbances [8, 9, 14-17]. 
None of the ALS patients in the present study had significant signs of mental disturbances before death. The HA in the ALS brains is reported to be as severe as that in the FTLD cases as presented in "ex vivo" MRI [7].

Recent studies have demonstrated frequent overlapping of the pathological features of a motor neuron, cognitive, and neurodegenerative diseases [18].

Although arterial hypertension is reported to occur in the early stages of ALS as a mechanism compensating for respiratory problems [19], the cerebrovascular lesions are infrequent [20-22]. The present study confirms the low cerebrovascular impact in ALS. This is similar to the previouslyreported observations in age-matched FTLD patients [23, 24].

ALS and FTLD are similar in that they are two faces of a TDP-43 proteinopathy [25]. Moreover, in both FTLD-associated ALS and the sporadic cases of ALS, a novel locus at $17 q 11.2$ has been observed $[26,27]$. However, the significance of these associations is difficult to ascertain.

The post-mortem observation of a high degree of HA in the ALS patients in the present study has to be considered an additional link of ALS with FTLD, in which further-extended severe atrophy is observed in the frontal and temporal lobes of the brain.

\section{Author Contributions}

Jacques De Reuck has designed the study. Together with Florent Auger and Nicolas Durieux he performed the MRI examinations. Claude-Alain Maurage and Vincent Deramecourt performed the macroscopic and histological examinations of the brains. Charlotte Cordonnier, Florence Pasquier, Didier Leys and Regis Bordet were responsible for clinical evaluation during life.

\section{Competing Interests}

The authors have declared that no competing interests exist.

\section{References}

1. Oskarsson B, Gendron TF, Staff NP. Amyotrophic lateral sclerosis: An update for 2018. Mayo Clin Proc. 2018; 93: 1617-1628.

2. Santillo AF, Scoglund L, Lindau M, Eeg-Olofsson KE, Tovi M, Engler $H$, et al. Frontotemporal dementia-amyotrophic lateral sclerosis complex is simulated by neurodegeneraton with brain iron accumulation. Alzheimer Dis Assoc Disord. 2009; 23: 298-300.

3. Cui B, Cui LY, Gao J, Lui MS, Li XG, Liu CY, et al. Cognitive impairment in Chinese patients with sporadic amyotrophic lateral sclerosis. PLos One. 2015; 10: e0137921.

4. Placek K, Baer CM, Elman L, McCluskey L, Hennessy L, Ferraro PM, et al. UNC13A polymorphism contributes to frontotemporal disease in sporadic amyotrophic lateral sclerosis. Neurobiol Aging. 2019; 73: 190-199.

5. De Reuck J, Devos D, Moreau C, Auger F, Durieux N, Deramecourt V, et al. Topographic distribution of brain iron deposition and small cerebrovascular lesions in amyotrophic lateral sclerosis and in frontotemporal lobar degeneration: A post-mortem 7.0-tesla magnetic resonance imaging study with neuropathological correlates. Acta Neurol Belg. 2017; 117: 873878. 
6. Konrad C, Ukas T, Nebel C, Arolt V, Toga AW, Narr KI. Defining the human hippocampus in cerebral magnetic resonance images: An overview of current segmentation protocols. Neuroimage. 2009; 47: 1185-1195.

7. De Reuck J, Auger F, Durieux N, Maurage CA, Deramecourt V, Cordonnier C, et al. Post-mortem 7.0-tesla magnetic resonance imaging of the hippocampus during normal aging and in neurodegenerative dementias. SunText Rev Neurosci Psychol. 2020; 1: 108.

8. Raaphorst J, van Tol MJ, de Visser M, van der Kool AJ, Majoie CB, van den Berg LH, et al. Prose memory impairment in amyotrophic lateral sclerosis patients is related to hippocampal volume. Eur J Neurol. 2015; 22: 547-554.

9. Christidi F, Karavasilis E, Rentzos M, Velonakis G, Zouvelou V, Xirou S, et al. Hippocampal pathology in amyotrophic lateral sclerosis; selective vulnerability of subfields and their associated projections. Neurobiol Aging. 2019; 84: 178-188.

10. De Reuck JL. Histopathological stainings and definitions of vascular disruptions in the elderly brain. Exp Geront. 2012; 47: 834-837.

11. Scheltens P, Leys D, Barkhof F, Huglo D, Weinstein HC, Vermersch P, et al. Atrophy of medial temporal lobes on MRI in "probable" Alzheimer's disease and normal aging: Diagnostic value and neuropsychological correlates. J Neurol Neurosurg Psychiatry. 1992; 55: 967-972.

12. De Reuck J, Auger F, Durieux N, Deramecourt V, Maurage CA, Pasquier F, et al. Cerebrovascular lesions during normal aging: A neuropathological study with 7.0-tesla magnetic resonance imaging. EC Neurology. 2018; 10: 229-235.

13. De Reuck J, Auger F, Cordonnier C, Deramecourt V, Durieux N, Pasquier F, et al. Comparison of 7.0-T T2*-magnetic resonance imaging of cerebral bleeds in post-mortem brain sections of Alzheimer patients with their neuropathological correlates. Cerebrovasc Dis. 2011; 31: 511-517.

14. Abdulla S, Machts J, Kaufmann J, Patrick K, Kollewe K, Dengler R, et al. Hippocampal degeneration in patients with amyotrophic lateral sclerosis. J Neurobiol Aging. 2014; 35: 26392645.

15. Steinbach R, Loewe K, Kaufmann J, Machts J, Kollewe K, Petri S, et al. Structural hallmarks of amyotrophic lateral sclerosis progression revealed by probablitistic fiber tractography. J Neurol. 2015; 262: 2257-2270.

16. Takeda T, Uchihara T, Arai N, Mizutani T, Iwata M. Progression of hippocampal degeneration in amyotrophic lateral sclerosis with and without memory impairment: Distinction from Alzheimer disease. Acta Neuropathol. 2009; 117: 35-44.

17. Tsuchiya K, Takashashi M, Schiotsu H, Akiyama H, Haga C, Watabiki S, et al. Sporadic amyotrophic lateral sclerosis with circumscribed temporal atrophy: A report of an autopsy case without dementia and with ubiquitinated intraneuronal inclusions. Neuropathology. 2002; 22: 308-316.

18. Coan G, Mitchell CS. An assessment of possible neuropathology and clinical relationships in 46 sporadic amyotrophic lateral sclerosis patient autopsies. Neurodegener Dis. 2015; 15: 301-312.

19. Moreau C, Brunaud-Danel V, Dallongeville J, Duhamel A, Laurier-Grymonprez L, De Reuck J, et al. Modifying effect of arterial hypertension on amyotrophic lateral sclerosis. Amyotroph Lateral Scler. 2012; 13: 194-201.

20. Sutedja NA, van der Schouw YT, Fischer K, Sizoo EM, Hulsman MH, Veldink JH, et al. Beneficial vascular risk profile is associated with amyotrophic lateral sclerosis. J Neurol Neurosurg Psychiatry. 2011; 82: 638-642. 
21. Kloumourtzoglou MA, Rotem RS, Seals RM, Gredal O, Hansen J, Weisskopf MG. Diabetes mellitus, obesity, and diagnosis of amyotrophic lateral sclerosis: A population-based study. JAMA Neurol. 2015; 72: 905-911.

22. Hollinger SK, Okosun IS, Mitchell CS. Antecedent disease and amyotrophic lateral sclerosis: What is protecting from whom? Front Neurol. 2016; 7: 47.

23. De Reuck J, Deramecourt V, Cordonnier C, Leys D, Pasquier F, Maurage CA. Cerebrovascular lesions in patients with frontotemporal lobar degeneration. Neurodegener Dis. 2012; 9: 170175.

24. De Reuck J, Deramecourt V, Cordonnier C, Auger F, Durieux N, Bordet R, et al. Detection of microbleeds in post-mortem brains of patients with frontotemporal lobar degeneration: A 7.0tesla magnetic resonance imaging study with neuropathological correlates. Eur J Neurol. 2012; 19: $1355-1360$.

25. Liscic RM, Grinberg LT, Zidar J, Gitcho MA, Cairns NJ. ALS and FTLD: Two faces of TDP-43 proteinopathy. Eur J Neurol. 2008; 15: 772-780.

26. Wilhelmsen K, Forman MS, Rosen HJ, Alving LI, Goldman J, Felger J, et al. 17-q-linked frontotemporal dementia-amyotrophic lateral sclerosis without tau mutations and $\alpha$-synuclein inclusies. Arch Neurol. 2004; 61: 398-406.

27. Fogh I, Ratti A, Gellera C, Lin K, Tiloca C, Moskvina V, et al. A genome-wide association metaanalysis identifies a novel locus at $17 q 11.2$ associated with sporadic amyotrophic lateral sclerosis. Hum Mol Genet. 2014; 23: 2220-2231.

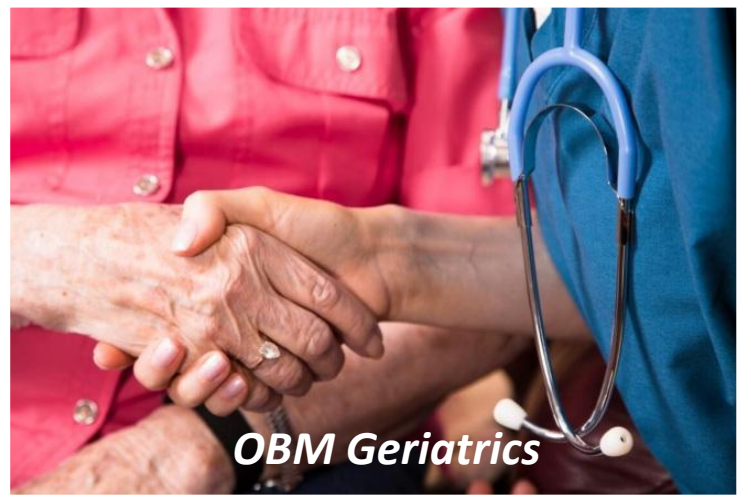

Enjoy $O B M$ Geriatrics by:

1. Submitting a manuscript

2. Joining in volunteer reviewer bank

3. Joining Editorial Board

4. Guest editing a special issue

For more details, please visit:

http://www.lidsen.com/journals/geriatrics 